LETTER TO JMG

\title{
Interleukin-1 cluster is associated with genetic risk for schizophrenia and bipolar disorder
}

\author{
S Papiol, A Rosa, B Gutiérrez, B Martín, P Salgado, R Catalán, B Arias, L Fañanás
}

J Med Genet 2004;41:219-223. doi: 10.1136/jmg.2003.012914

S chizophrenia and affective psychoses are severe and prevalent psychiatric disorders described in all cultures and populations. Whether these functional psychoses are two distinct disorders, or are closely related in aetiology, has been debated in the literature during the last century. ${ }^{1-4}$

Several studies have suggested that schizophrenia and bipolar disorder are on a continuum of liability. Psychopathological dimensions and psychiatric symptoms shared by both groups of patients would be compatible with this overlap. ${ }^{5}$ Likewise, other risk factors, such as cerebral ventricle enlargement, ${ }^{6}$ markers of prenatal suffering, ${ }^{7}$ or life events, ${ }^{8}$ have been described in both mental disorders. Recent molecular linkage studies have suggested the possible existence of shared disease loci for both disorders. ${ }^{9}$ Of special interest are the family studies showing that first degree relatives of bipolar patients have a three times increased risk for schizophrenia compared with first degree relatives of controls. ${ }^{11}{ }^{11}$ These data suggest the presence of a common genetic risk background in both disorders. However, it should be noted that other family studies have not been able to replicate these latter results. ${ }^{12} 13$

Over the last decade, several studies have reported an imbalance in pro-inflammatory/anti-inflammatory cytokines or their soluble receptors level in plasma or cerebrospinal fluid of schizophrenic and bipolar disorder patients. ${ }^{14}{ }^{15}$ These results have been replicated by recent studies in both diagnostic groups. ${ }^{16} 17$

Genes coding for some of these cytokines are located on the IL-1 cluster within chromosome $2 \mathrm{q} 13$. This cluster contains nine genes of the IL- 1 family of cytokines $(I L-1 A, I L-1 B, I L$ $I R N$, and $I L-I F 5-F 10) .{ }^{18}$ Several polymorphic variants of these genes have been associated with human diseases. ${ }^{19}$

The IL- $1 \beta$ gene $(I L-1 B)$ consists of seven exons with an extension of $7 \mathrm{~kb}$ and codes for a precursor form (proIL-1 $\beta$ ) which is cleaved by a protease (ICE) to give the active IL-1 $\beta$ form. This pro-inflammatory cytokine is involved in acute and chronic neurodegeneration ${ }^{20}$ and in embryonic development of the CNS. ${ }^{21}$ During CNS neurodevelopment, IL-1 $\beta$ promotes proliferation and production of cytokines and trophic factors, such as nerve growth factor (NGF), in astrocytes $^{22}$ and inhibits normal expression of brain-derived neurotrophic factor (BDNF). ${ }^{21}$ In addition, IL- 1 ( $\alpha$ and $\beta$ ) participates in differentiation of mesencephalic progenitor cells into dopaminergic neurons in cell culture. ${ }^{23}$

On the other hand, the IL-1Ra gene $(I L-I R N)$ consists of seven exons in a region of $16 \mathrm{~kb}$, and several splice variants can be obtained from the coding sequence. Its product, IL-1 receptor antagonist (IL-1Ra), is an endogenous antagonist at IL- 1 receptors and modulates the action of IL- 1 agonists. Altered levels of IL-1Ra have been described in the pathogenesis of several diseases where inflammatory or autoimmune processes are involved. ${ }^{24}$

Recent studies have shown that drug-naive schizophrenic patients exhibit a significant increase in both IL-1 $\beta$ and ILIRa plasma levels when compared with healthy con-

\section{Key points}

- Several studies have suggested that schizophrenia and bipolar disorder are on a continuum of liability. Both disorders share psychopathological dimensions, psychiatric symptoms, and risk factors. Furthermore, family and linkage studies lend credence to the presence of a common genetic risk background.

- Altered levels of cytokines have been found in these mental disorders. Genes coding for interleukin-1 $\beta$ (IL$1 \beta$ ) and interleukin-1 receptor antagonist (IL-1Ra) are possible candidate genes due to the role of these cytokines in neurodevelopment and neurodegeneration, processes which might be involved in the origin of psychosis.

- We analysed a polymorphism in the promoter region $(-511)$ of the IL-1 $\beta$ gene and an 86 bp VNTR in intron 2 of the IL-1Ra gene in schizophrenic and bipolar patients and in healthy controls.

- A significant excess of the haplotypic combination -511 allele*1/VNTR allele*2 was found both in schizophrenic $(P=0.0015 ; O R=2.49195 \%$ confidence interval (CI): 1.33 to 4.64$))$ and bipolar patients $(P=0.004 ; O R=2.26(95 \% \mathrm{Cl}: 1.22$ to 4.17$))$ when compared with controls. The highest risk conferred by this risk haplotype was detected in bipolar patients with a family history of schizophrenia, bipolar disorder, or severe major depression $(P=0.00009 ; \quad O R=3.18$ (95\% Cl: 1.66 to 6.05$)$ ).

- IL-1 cluster genetic variability may represent a shared genetic susceptibility factor both for schizophrenia and bipolar disorder.

trols. $^{14}{ }^{16} 25$ : it is generally agreed that regulatory processes affecting IL- 1 function are, at least in part, determined by genetic variation. ${ }^{26}$ Thus, production of IL- $1 \beta$ and IL-1Ra may be modulated by the effect of polymorphisms in the IL- 1 cluster.

Unfortunately, data regarding the functional effect of these polymorphisms on cytokine production are unclear and even contradictory. Taken together, all functional data suggest that allelic status in both $I L-1 B$ and $I L-I R N$ genes determines, acting coordinately, the levels of these proteins. ${ }^{27-29}$

Over the last few years, genetic studies have shown an association of polymorphisms in the IL-1 cluster with either schizophrenia or clinical subgroups of this disorder. ${ }^{26} 3031$

Abbreviations: $\mathrm{BP}$, bipolar disorder; $\mathrm{Cl}$, confidence intervals; $\mathrm{FH}$, family history; OR, odds ratio 
The aim of the present study was to investigate the role of certain polymorphic variants of genes of the IL-1 gene cluster in susceptibility to functional psychosis. For this purpose we analysed an SNP at the promoter region (-511C/T; rs16944) of the $I L-I B$ gene and a pentallelic $86 \mathrm{bp}$ tandem repeat in intron 2 of the $I L-I R N$ gene in a sample of 78 schizophrenic patients, 88 bipolar disorder patients, and 176 healthy controls.

\section{MATERIALS AND METHODS Subjects}

The schizophrenic patients' sample consisted of 78 unrelated DSM-IV diagnosed patients (mean age: 31.1 years, SD 7.5 ) from two public mental health centres in Barcelona: the Mental Health Service of the Eixample district $(n=38)$ and the Institut Municipal d'Urgències Psiquiàtriques (IMPU) $(n=40)$. Diagnoses were determined by experienced psychiatrists using the Spanish version of the Structural Clinical Interview for DSM-IV (SCID-I). The mean evolution time in patients since the first episode was 9.9 years (SD 7.8) and the mean age at onset, defined as the age at which psychotic symptoms first became evident, was 21.2 years (SD 4.6).

A total of 88 unrelated patients meeting the DSM-III-R criteria for bipolar disorder (mean age: 44.8 years, SD 14.9) recruited from Clínica Mental Santa Coloma of Barcelona constituted the bipolar disorder patients' sample. The mean evolution time in patients since the first episode was 15.9 years (SD 12.9) and the mean age at onset was 29.5 years (SD 11.6). Information about any family psychiatric history of schizophrenia, bipolar disorder (BP), or severe major depression was determined in bipolar patients using the Spanish version of the structured interview Family History-Research Diagnostic Criteria (FH-RDC). ${ }^{32}$ This information was obtained by experienced psychiatrists from personal interviews with at least two healthy first degree relatives of each patient. According to this interview, $67 \%$ of the sample showed a positive family history of severe mental disorder (schizophrenia, bipolar disorder, and/or severe major depression) in at least a first degree relative. This sample consisted of a group of inpatients presenting an extremely severe outcome (see Vallès et $a l^{11}$ for additional details about the clinical profile of this sample and its psychiatric familial morbid risk).

The control group consisted of 176 healthy individuals (mean age: 39.82 years, SD 10.35) recruited from the catchment area of the hospitals involved in this study and can be considered to be representative of the general population of Barcelona. These subjects were interviewed in order to verify that there was no personal history of severe mental illness. Additionally, the Spanish version of the 28item General Health Questionnaire $(\mathrm{GHQ})^{33}$ was used to assess current mental condition. All controls and patients showing a positive personal history of neurological disease, cancer, diabetes, or drug or alcohol abuse were excluded from the study.

All cases and controls were of white Spanish origin, shared similar sociodemographic profiles and were comparable as regards the geographical origin of their families.

All subjects gave written informed consent for the study prior to inclusion. The study protocol was approved by the ethical committees of each centre.

\section{Molecular analysis}

Genomic DNA was extracted from blood samples using standard phenol-cloroform methods. The -511 AvaI polymorphic site located on the promoter region of the $I L-1 \beta$ gene and the $86 \mathrm{bp}$ repeat of the $I L-I R a$ gene were genotyped as described previously by Katila et al. ${ }^{25}$ Allele 1 ( $-511 \mathrm{C}$ ) of the $I L-1 \beta$ gene completes an AvaI restriction site giving products of $190+114 \mathrm{bp}$ after enzymatic digestion, while allele 2 $(-511 \mathrm{~T})$ gives an intact product of $304 \mathrm{bp}$. When the 86 bp repeat in intron 2 of the $I L-1 R a$ gene was analysed, five alleles (Al-A5) were detected in accordance with the number of repeats (2-6).

\section{Statistical analysis}

The presence of Hardy-Weinberg equilibrium for genotype frequencies was defined in the samples of patients and controls using $\chi^{2}$ tests. Simple $\chi^{2}$ tests of independence were also performed to confirm the presence or absence of allele or genotype associations. Odds ratios (OR) with $95 \%$ confidence intervals (CI) were estimated for the effects of high-risk genotypes and alleles.

The ARLEQUIN program was used to estimate the haplotypes and their frequencies according to genotype information (expectation maximisation (EM) algorithm) as well as to determine the statistical significance of linkage disequilibrium. ${ }^{34}$

\section{RESULTS}

Frequencies observed for genotypes and alleles in control, bipolar, and schizophrenic samples are shown in tables 1 and 2. Given the allelic frequencies obtained in the general population for the $-511 \mathrm{C} / \mathrm{T}$ polymorphism, our sample had $80 \%$ power $(95 \% \mathrm{CI})$ to detect an allelic association that confers a risk greater than or equal to 2.50 (in schizophrenic patients) or 2.39 (in bipolar patients). In the case of $86 \mathrm{bp}$ VNTR, our sample had $80 \%$ power $(95 \% \mathrm{CI})$ to detect an allelic association that confers a risk greater than or equal to 2.33 (schizophrenia) or 2.25 (bipolar disorder). All groups showed Hardy-Weinberg equilibrium for the analysed genetic variability (data not shown). No differences were observed when allele, genotype, and haplotype frequencies were compared between females and males in both patient and control groups (data not shown).

An excess of allele $1(-511 C)$ close to statistical significance was detected when allelic frequencies of the $-511 \mathrm{C} / \mathrm{T}$ polymorphism were analysed in schizophrenic patients compared to controls (allele: $\chi^{2}=3.79, \mathrm{P}=0.051$; $\mathrm{OR}=1.50$ (95\% CI: 0.98 to 2.31$)$ ) (table 1). No statistical differences with controls were found for allelic or genotypic frequencies distribution in the bipolar disorder sample.

For analysis of the $I L-1 R a$ gene 86 bp repeat, alleles A3, A4, and A5 were considered as a single allele due to their low frequencies. Likewise, genotypes containing these infrequent alleles were also considered as a single genotype (table 2). Allelic and genotypic frequencies of schizophrenic and bipolar patients did not differ from those found in controls.

There is evidence supporting the existence of strong linkage disequilibrium between IL-1 cluster loci. ${ }^{35}{ }^{36}$ Given the genotypic frequencies in our samples, a haplotypic analysis was conducted in order to estimate haplotypic frequencies (table 3). Linkage between this pair of loci was found to be significant in both the control $(\mathrm{P}<0.00001)$ and bipolar $(\mathrm{P}=0.01)$ samples, but not in the schizophrenic sample.

In order to be consistent with previous studies, haplotypes containing A3, A4, or A5 alleles of the IL-1RN polymorphism were considered as a single haplotypic combination due to their low frequencies. The estimated haplotypic frequencies in our Spanish control sample were similar to those described in previous studies in North American white, Scottish, and Polish populations. ${ }^{37} 38$

Statistically significant differences were found when we compared the haplotype distribution of cases and controls (schizophrenia: $\chi^{2}=12.70, \quad \mathrm{P}=0.012 ;$ bipolar disorder: $\left.\chi^{2}=9.81, \mathrm{P}=0.043\right)$. It should be noted that the haplotypic combination -511 (allele 1)-VNTR (allele 2) was increased 
Table 1 Genotype and allele frequencies of the $-511 \mathrm{C} / \mathrm{T}$ polymorphism in patients with schizophrenia, patients with bipolar disorder (BP) and a positive family history $(\mathrm{FH}+)$, and the control group

\begin{tabular}{|c|c|c|c|c|c|c|}
\hline \multirow[b]{2}{*}{ Diagnosis } & \multirow[b]{2}{*}{$n$} & \multicolumn{3}{|c|}{ Genotype frequency $(\%)$} & \multicolumn{2}{|c|}{ Allele frequency $(\%)$} \\
\hline & & 1.1 & 1.2 & 2.2 & 1 & 2 \\
\hline Schizophrenia & 78 & $39(50.0 \%)$ & $33(42.3 \%)$ & $6(7.7 \%)$ & $111(71.2 \%)$ & $45(28.8 \%)$ \\
\hline $\begin{array}{l}\text { Bipolar disorder } \\
\text { (BP) }\end{array}$ & 88 & $38(43.2 \%)$ & $43(48.8 \%)$ & $7(8.0 \%)$ & $119(67.6 \%)$ & 57 (32.4\%) \\
\hline $\mathrm{BP} \mathrm{FH}+$ & 59 & $27(45.8 \%)$ & $27(45.8 \%)$ & $5(8.5 \%)$ & $81(68.6 \%)$ & $37(31.4 \%)$ \\
\hline Controls & 176 & $69(39.2 \%)$ & $81(46.0 \%)$ & $26(14.8 \%)$ & $219(62.2 \%)$ & $133(37.8 \%)$ \\
\hline
\end{tabular}

$\mathrm{FH}+$ : patients with at least a first degree relative suffering from schizophrenia, bipolar disorder, or severe major depression.

Schizophrenia $v$ controls: allele: $\chi^{2}=3.79, \mathrm{P}=0.051$; $\mathrm{OR}=1.50$ (95\% Cl: 0.98 to 2.31 ); genotype: $\chi^{2}=4.26$,

$\mathrm{P}=0.119$.

Bipolar disorder $v$ controls: allele: $\chi^{2}=1.48, P=0.223 ; \mathrm{OR}=1.27$ (95\% Cl: 0.85 to 1.90); genotype: $\chi^{2}=2.89$; $\mathrm{P}=0.235$.

Bipolar disorder $\mathrm{FH}+v$ controls: allele: $\chi^{2}=1.58, \mathrm{P}=0.208$; $\mathrm{OR}=1.33$ (95\% Cl: 0.84 to 2.14); genotype: $\chi^{2}=1.79 ; \mathrm{P}=0.408$.

from two to three times in patients compared to controls. Thus, for the next comparisons we considered all possible haplotypic combinations as a single group except for the -511 (allele 1)-VNTR (allele 2) combination in order to estimate the risk conferred by this haplotype. When odds ratios were calculated, this haplotypic combination was found to confer a significantly increased risk both for schizophrenia $\left(\chi^{2}=9.99, \quad \mathrm{P}=0.0016 ; \quad \mathrm{OR}=2.49 \quad\right.$ (95\% CI: 1.33 to 4.64$))$ and bipolar disorder $\left(\chi^{2}=8.09, \mathrm{P}=0.004\right.$; $\mathrm{OR}=2.26(95 \% \mathrm{CI}: 1.22$ to 4.17$))$. When only individuals of the bipolar sample with a positive family history of schizophrenia, bipolar disorder, or severe major depression in at least a first degree relative were considered, the effect of this haplotype became even more important $\left(\chi^{2}=15.41\right.$, $\mathrm{P}=0.00009 ; \mathrm{OR}=3.18$ (95\% CI: 1.66 to 6.05$)$ )

\section{DISCUSSION}

To our knowledge, this is first time that IL-l related polymorphisms have been analysed in a sample of bipolar patients. Previous studies have suggested that these polymorphisms of the $I L-1 \beta$ and $I L-I R N$ genes may influence susceptibility to schizophrenia. Katila et al ${ }^{26}$ reported a positive association with schizophrenia for the combination -511 (allele 1)-VNTR (allele 1), as opposed to -511 (allele 1)VNTR (allele 2) in the present study. Meisenzahl et al. ${ }^{30}$ and Rosa et al..$^{31}$ described an association of -511 (allele 2) with schizophrenia and, more specifically, with clinical subgroups of this disorder. Meisenzahl and colleagues described an excess of allele 2 in schizophrenic patients showing decreases in bifrontal-temporal gray matter volume and generalised white matter tissue deficits. Rosa and colleagues found the same allele 2 associated with depressive dimension in schizophrenia. In addition, other genetic studies have reported a negative association between the $I L-1 \beta$ gene and schizophrenia. ${ }^{39-41}$ It should be noted that none of these studies used the haplotypic approach presented in the current report: owing to the strong linkage disequilibrium between loci located on the IL-1 cluster, analysis of haplotypes would be the most appropriate method to study the involvement of this genomic region in psychiatric disorders.

Our findings on the strongest effect size observed in the bipolar patients with a positive family history should be interpreted carefully. As mentioned above, this sample presents an extremely severe outcome. These patients were selected for severity and chronicity of illness course and displayed high rates of psychotic symptoms and high rates of schizophrenia in their first degree relatives. All these data suggest that the positive family history subgroup would include those patients with a higher genetic loading, which would allow us to detect the increased effect found in these patients. In this sense it is interesting to note that recent findings implicating neuregulin 1 gene as a schizophrenia susceptibility locus also reported that a risk haplotype was enriched in those schizophrenic patients showing a positive family history of schizophrenia. ${ }^{42}$

Cytokine production seems, at least in part, to be genetically determined, but the exact functional role of these polymorphisms of the $I L-I B$ and $I L-I R N$ genes remains

Table 2 Genotype and allele frequencies of the intron 2 VNTR polymorphism in patients with schizophrenia, patients with bipolar disorder (BP) with a positive family history $(\mathrm{FH}+)$, and the control group

\begin{tabular}{|c|c|c|c|c|c|c|c|c|}
\hline \multirow[b]{2}{*}{ Diagnosis } & \multirow[b]{2}{*}{$n$} & \multicolumn{4}{|c|}{ Genotype frequency (\%) } & \multicolumn{3}{|c|}{ Allele frequency (\%) } \\
\hline & & $\mathrm{Al} / \mathrm{Al}$ & A1/A2 & A2/A2 & Others & Al & A2 & $\mathrm{A} 3, \mathrm{~A} 4, \mathrm{~A} 5$ \\
\hline Schizophrenia & 78 & 35 (44.9\%) & $34(43.6 \%)$ & $4(5.1 \%)$ & $5(6.4 \%)$ & 108 (69.2\%) & $43(27.6 \%)$ & $5(3.2 \%)$ \\
\hline $\begin{array}{l}\text { Bipolar disorder } \\
\text { (BP) }\end{array}$ & 88 & $36(40.9 \%)$ & 35 (39.8\%) & $9(10.2 \%)$ & $8(9.1 \%)$ & 111 (63.1\%) & 57 (32.4\%) & $8(4.5 \%)$ \\
\hline $\mathrm{BP} F \mathrm{FH}_{+}$ & 59 & $22(37.3 \%)$ & $26(44.1 \%)$ & $6(10.2 \%)$ & $5(8.4 \%)$ & 72 (61.0\%) & $41(34.7 \%)$ & 5 (4.3\%) \\
\hline Controls & 175 & $91(52.0 \%)$ & $62(35.4 \%)$ & $11(6.3 \%)$ & $11(6.3 \%)$ & 250 (71.4\%) & $88(25.1 \%)$ & $12(3.5 \%)$ \\
\hline
\end{tabular}

$\mathrm{FH}+$ : patients with, at least, a first degree relative suffering from schizophrenia, bipolar disorder, or severe major depression.

For all comparisons, A3, A4, and A5 were considered a single allele, and genotypes containing the A3, A4, or A5 allele were considered a single genotype.

Schizophrenia $v$ controls: allele: $\chi^{2}=0.33, \mathrm{P}=0.84$; genotype: $\chi^{2}=1.62, \mathrm{P}=0.65$.

Bipolar disorder $v$ controls: allele: $\chi^{2}=3.81, \mathrm{P}=0.15$; genotype: $\chi^{2}=3.63 ; \mathrm{P}=0.30$

Bipolar disorder $\mathrm{FH}+v$ controls: allele: $\chi^{2}=4.50, \mathrm{P}=0.105$; genotype: $\chi^{2}=4.08 ; \mathrm{P}=0.253$. 
Table 3 Estimated haplotype frequencies of the $-511 \mathrm{C} / \mathrm{T} /$ intron 2 VNTR polymorphisms in patients with schizophrenia, patients with bipolar disorder (BP) with a positive family history $(\mathrm{FH}+)$, and the control group

\begin{tabular}{lccllll}
\hline \multicolumn{7}{c}{ Haplotype frequency (\%) } \\
\cline { 3 - 7 } Diagnosis & $\boldsymbol{n}$ & $\begin{array}{l}\text { VNTR(A1) } \\
\text { V11(1)- }\end{array}$ & $\begin{array}{l}-511(2)- \\
\text { VNTR(A2) }\end{array}$ & $\begin{array}{l}-511(2)- \\
\text { VNTR(A1) }\end{array}$ & $\begin{array}{l}-511(1)- \\
\text { VNTR(A2) }\end{array}$ & Others \\
\hline Schizophrenia & 78 & $81(51.8 \%)$ & $17(10.8 \%)$ & $27(17.4 \%)$ & $26(16.7 \%)$ & $5(3.3 \%)$ \\
Bipolar disorder & 88 & $85(48.1 \%)$ & $30(16.8 \%)$ & $26(15.0 \%)$ & $27(15.5 \%)$ & $8(4.6 \%)$ \\
(BP) & 59 & $52(44.1 \%)$ & $17(14.5 \%)$ & $20(16.9 \%)$ & $24(20.3 \%)$ & $5(4.2 \%)$ \\
BP FH+ & 175 & $179(51.3 \%)$ & $62(17.8 \%)$ & $71(20.2 \%)$ & $26(7.3 \%)$ & $12(3.4 \%)$ \\
Controls & &
\end{tabular}

$\mathrm{FH}+$ : patients with, at least, a first degree relative suffering from schizophrenia, bipolar disorder, or severe major depression.

For all comparisons, the haplotypes containing A3, A4, or A5 alleles of the IL-1RN VNTR were considered as a single haplotypic combination.

Schizophrenia $v$ controls: haplotype distribution: $\chi^{2}=12.70, P=0.012$

Bipolar disorder $v$ controls: haplotype distribution: $\chi^{2}=9.81, P=0.043$

Bipolar disorder $\mathrm{FH}+v$ controls: haplotype distribution: $\chi^{2}=15.90, \mathrm{P}=0.0031$.

Schizophrenia $v$ controls: haplotype $\left(-511\right.$ (1)-VNTR (A2)) $v$ other haplotypes: $\chi^{2}=9.99, P=0.0015 ; O R=2.49$

(95\% Cl: 1.33 to 4.64 ).

Bipolar disorder $v$ controls: haplotype $\left(-511\right.$ (1)-VNTR (A2)) $v$ other haplotypes: $\chi^{2}=8.09, P=0.004 ;$ OR $=2.26$ (95\% Cl: 1.22 to 4.17$)$.

Bipolar disorder FH+ v controls: haplotype (-511(1)-VNTR (A2)) $v$ other haplotypes: $\chi^{2}=15.41, P=0.00009$;

$\mathrm{OR}=3.18(95 \% \mathrm{Cl}: 1.66$ to 6.05$)$.

unclear. Although it has been comprehensively reported that IL- $1 \beta$ exerts a pro-inflammatory function and IL-1Ra plays an anti-inflammatory role in the immune response, the underlying mechanisms by which these cytokines act are not yet fully understood. We hypothesise that an imbalance in the ratio between pro-inflammatory and anti-inflammatory cytokines may affect embryonic neurodevelopment and promote neurodegeneration in adulthood. ${ }^{20}{ }^{21}$ Additionally, IL- $1 \beta$ plays a key role in the dopaminergic differentiation of neural progenitors. ${ }^{23}$ It should be mentioned that alterations in the dopaminergic system have been classically related to the origin of functional psychoses and, particularly, to the origin of positive symptoms. According to evidence mentioned above, the polymorphic regions analysed in this study, which are thought to confer subtle changes in the expression pattern of the $I L-I B$ and $I L-I R N$ genes, could contribute, with a moderate effect, to destabilising the pro-inflammatory/antiinflammatory equilibrium during neurodevelopment.

On the other hand, we cannot exclude the possibility that other genetic variants may exist near or within the IL- 1 cluster in linkage disequilibrium with the genetic variability analysed in this study and be directly involved in the origin of both mental disorders.

Some methodological limitations should be taken into account when interpreting our results. Although the subjects were of white Spanish origin and from the same community, we cannot rule out the possibility of a population structure effect in our findings. Further studies employing either larger or family-based samples, as well as finer haplotype mapping of additional polymorphisms in the IL-1 cluster, are needed in order to confirm or reject these results.

In conclusion, our data suggest that genetic variability in the IL-1 cluster may contribute to a shared genetic risk background of vulnerability for both schizophrenia and bipolar disorder.

\section{ACKNOWLEDGEMENTS}

Sergi Papiol was supported by a grant from the Ministry of Education and Culture of Spain (MECD). The authors would like to thank Vicenç Vallès, Roser Guillamat, and Rafael Penadés for their participation in the collection of bipolar and schizophrenic samples. We would like to thank the participating patients and their families, whose generous contributions have made this study possible.

\section{Authors' affiliations}

S Papiol, A Rosa, B Gutiérrez, B Martín, B Arias, L Fañanás, Unitat d'Antropologia, Departament de Biologia Animal, Facultat de Biologia, Universitat de Barcelona, Diagonal 645, Barcelona 08028, Spain P Salgado, Clínica Mental Santa Coloma, Barcelona, Spain R Catalán, Centre de Salut Mental Esquerre de l'Eixample, Hospital Clínic i Provincial de Barcelona, and Institut d'Investigació Biomédica Agustí Pi i Sunyer (IDIBAPS), Barcelona, Spain

This study was supported by a grant from Fundació "La Caixa" (99111-000).

Correspondence to: L Fañanás, Unitat d'Antropologia, Departament de Biologia Animal, Facultat de Biologia, Universitat de Barcelona, Diagonal 645, 08028 Barcelona, Spain; sergi.papiol@ub.edu

Received 30 July 2003

Accepted 16 November 2003

\section{REFERENCES}

1 Crow TJ. Con: the demise of the Kraepelinian binary systems as a prelude to genetic advance. In: Gerson ES, Cloninger CR, eds. Genetic approaches to mental disorders. Washington, DC: American Psychiatry Press, 1994:163-92.

2 Crow TJ. From Kraepelin to Kretschmer leavened by Schneider: the transition from categories of psychosis to dimensions of variation intrinsic to Homo sapiens. Arch Gen Psychiatry 1998;55:502-4.

3 Kendler KS, Walsh D. The structure of psychosis: syndromes and dimensions. Arch Gen Psychiatry 1998;55:508-9.

4 Kendler KS, Karkowski LM, Walsh D. The structure of psychosis: latent class analysis of probands from the Roscommon Family Study. Arch Gen Psychiatry 1998;55:492-9.

5 Maziade M, Roy MA, Martinez M, Cliche D, Fournier JP, Garneau Y, Nicole L, Montgrain N, Dion C, Ponton AM. Negative psychoticism and disorganised dimensions in patients with familial schizophrenia or bipolar disorder: continuity and discontinuity between major psychoses. Am J Psychiatry 1995; 152:1458-63.

6 Elkis H, Friedman L, Wise A, Meltzer HY. Metaanalyses of studies of ventricular enlargement and cortical sulcal prominence in mood disorders. Comparisons with controls or patients with schizophrenia. Arch Gen Psychiatry 1995;52:735-46.

7 Gutiérrez B, Van Os J, Vallès V, Guillamat R, Campillo M, Fañanás L. Congenital dermatoglyphic malformations in severe bipolar disorder. Psychiatry Res 1998;78:133-40.

8 Bebbington P, Wilkins S, Jones PB, Foerster A, Murray R, Toone B, Lewis S. Life events and psychosis. Initial results from the Camberwell Collaborative Psychosis Study. Br J Psychiatry 1993; 162:72-9

9 Berrettini WH. Are schizophrenic and bipolar disorders related? A review of family and molecular studies. Biol Psychiatry 2000;48:531-8.

10 Sham PC, Jones P, Russell A, Gilvarry K, Bebbington P, Lewis S, Toone B, Murray R. Age at onset, sex, and familial psychiatric morbidity in 
schizophrenia. Camberwell Collaborative Psychosis Study. Br J Psychiatry 1994; 165:466-73.

11 Vallès V, Van Os J, Guillamat R, Gutiérrez B, Campillo M, Gento P, Fañanás L. Increased morbid risk for schizophrenia in families of in-patients with bipolar illness. Schizophr Res 2000;42:83-90.

12 Gershon ES, Hamovit J, Guroff JJ, Dibble E, Leckman JF, Sceery W, Targum SD, Nurnberger JI, Goldin LR, Bunney WE. A family study of schizoaffective, bipolar I, bipolar II, unipolar, and normal control probands. Arch Gen Psychiatry 1982;39:1157-67.

13 Weissman MM, Gershon ES, Kidd KK, Prusoff BA, Leckman JF, Dibble E, Hamovit J, Thompson WD, Pauls DL, Guroff JJ. Psychiatric disorders in the relatives of probands with affective disorders. Arch Gen Psychiatry 1984:41:13-21.

14 Katila H, Appelberg B, Hurme M, Rimon R. Plasma levels of interleukin-1 beta and interleukin- 6 in schizophrenia, other psychosis and affective disorders. Schizophr Res 1994; 12:29-34.

15 Maes M, Bosmans E, Calabrese J, Smith R, Meltzer HY. Interleukin-2 and interleukin-6 in schizophrenia and mania: effects of neuroleptics and mood stabilizers. J Psychiatr Res 1995;29:141-52.

16 Theodoropoulou ST, Spanakos G, Baxevanis CN, Economou M, Gritzapis AD, Papamichail MP, Stefanis CN. Cytokine serum levels, autologous mixed lymphocyte reaction and surface marker analysis in never medicated and chronically medicated schizophrenic patients. Schizophr Res 2001;47:13-25.

17 Tsai SY, Chen KP, Yang YY, Chen CC, Lee JC, Singh VK, Leu SJ. Activation of indices of cell-mediated immunity in bipolar mania. Biol Psychiatry 1999;45:989-94.

18 Nicklin MJH, Barton JL, Nguyen M, FitzGerald MG, Duff GW, Kornman K. A sequence-based map of the nine genes of the human interleukin-1 cluster. Genomics 2002;79:718-25.

19 Haukim N, Bidwell JL, Smith AJ, Keen U, Gallagher G, Kimberly R, Huizinga T, McDermott MF, Oksenberg J, McNicholl J, Pociot F, Hardt C, D'Alfonso S. Cytokine gene polymorphism in human disease: on-line databases, supplement 2. Genes Immun 2002;3:313-30.

20 Allan SM, Rothwell NJ. Cytokines and acute neurodegeneration. Nat Rev Neurosci 2001;2:734-44.

21 Nawa H, Takahashi M, Patterson PH. Cytokine and growth factor involvement in schizophrenia-support for the developmental model. Mol Psychiatry 2000;5:594-603.

22 Friedman WJ, Thakur S, Seidman L, Rabson AB. Regulation of nerve growth factor mRNA by interleukin-1 in rat hippocampal astrocytes is mediated by NfkappaB. J Biol Chem 1996;271:31115-20.

23 Potter ED, Ling ZD, Carvey PM. Cytokine-induced conversion of mesencephalic-derived progenitor cells into dopamine neurons. Cell Tissue Res 1999;296:235-46.

24 Arend WR. The balance between IL-1 and IL-1Ra in disease. Cytokine Growth Factor Rev 2002:13:323-40.

25 Akiyama K. Serum levels of soluble IL-2 receptor alpha, IL-6 and IL-1 receptor antagonist in schizophrenia before and during neuroleptic administration. Schizophr Res 1999;37:97-106.

26 Katila H, Hänninen K, Hurme M. Polymorphisms of the interleukin-1 gene in schizophrenia. Mol Psychiatry 1999;4:179-81

27 Hurme M, Santtila S. IL-1 receptor antagonist (IL-1Ra) plasma levels are coordinately regulated by both IL-1 Ra and IL-1 beta genes. Eur J Immunol 1998;28:2598-602.
28 Santtila S, Savinainen K, Hurme M. Presence of the IL-1 Ra allele 2 (ILIRN*2) is associated with enhanced IL-1 beta production in vitro. Scand J Immunol 1998;47:195-98

29 Vamvakopoulos J, Green C, Metcalfe S. Genetic control of IL-1beta bioactivity through differential regulation of the IL-1 receptor antagonist. Eur J Immunol 2002;32:2988-96.

30 Meisenzahl EM, Rujescu D, Kirner A, Giegling I, Kathmann N, Leisinger G, Maag K, Hegerl U, Hahn K, Moller HJ. Association of an interleukin-1 beta genetic polymorphism with altered brain structure in patients with schizophrenia. Am J Psychiatry 2001;158:1316-19.

31 Rosa A, Peralta V, Papiol S, Cuesta MJ, Serrano F, Martínez-Larrea A, Fañanás $\mathrm{L}$. The effect of the IL-1 beta gene in the complex phenotype of psychosis. Am J Med Genet 2002; 1 14:867-8.

32 Endicott J, Andreasen N, Spitzer RL. Family History-Research Diagnostic Criteria. New York: New York State Psychiatric Institute, Biometrics Research, 1975.

33 Goldberg DP, Hillier VF. Scaled version of the General Health Questionnaire. Psychol Med 1979:9:139-45.

34 Schneider S, Kuefer JM, Roessli D, Excoffier L. Arlequin: a soffware environment for the analysis of population genetics datagenetics and biometry. LabArlequin: a software environment for the analysis of population genetics data. Geneva: Genetics and Biometry Lab, University of Geneva, 1996.

35 Cox A, Camp NJ, Nicklin MJ, di Giovine FS, Duff GW. An analysis of linkage disequilibrium in the interleukin-1 cluster, using a novel grouping method for multiallelic markers. Am J Hum Genet 1998;62:1180-8.

36 Pessi T, Karjalainen J, Hulkkonen J, Nieminen MM, Hurme M. A common IL-1 complex haplotype is associated with an increased risk of atopy. J Med Genet 2003;40:e66.

37 El-Omar EM, Carrington M, Chow W-H, McColl KEL, Bream JH, Young HA, Herrera J, Lissowska J, Yuan CC, Rothman N, Lanyon G, Martin M, Fraumeni JF, Rabkin CS. Interleukin-1 polymorphisms associated with increased risk of gastric cancer. Nature 2000;404:398-402.

38 Tseng LH, Chen PJ, Lin MT, Shau WY, Chaung SM, Martin PJ, Hansen JA. Single nucleotide polymorphisms in intron 2 of the human interleukin-1 receptor antagonist (IL-1 1 Ra) gene: further definition of the IL-1 beta and IL1 Ra polymorphisms in North American Caucasians and Taiwanese Chinese. Tissue Antigens $2001 ; 57: 318-24$.

39 Tatsumi M, Sasaki T, Sakai T, Kamijima K, Fukuda R, Kunugi H, Hattori M, Nanko S. Genes for interleukin-2 receptor beta chain, interleukin-1 beta and schizophrenia: no evidence for the association or linkage. Am J Med Genet 1997:74:338-41.

40 Laurent C, Thibaut F, Ravassard P, Campion D, Samolyk D, Lafargue C, Petit M, Martinez M, Mallet J. Detection of two new polymorphic sites in the human interleukin-1 beta gene: lack of association with schizophrenia in a French population. Psychiatr Genet 1997;7:103-5.

41 Yang J, Si T, Ling Y, Ruan Y, Han Y, Wang X, Zhou M, Zhang H, Kong Q, Liu C, Li X, Yu Y, Liu S, Shu L, Ma D, Wie J, Zhang D. Association study between interleukin-1beta gene and schizophrenia. Life Sci 2003;72:3017-21.

42 Williams NM, Preece A, Spurlock G, Norton N, Williams HJ Zammit S, O'Donovan MC, Owen M. Support for genetic variation in neuregulin 1 and susceptibility to schizophrenia. Mol Psychiatry 2003;8:485-87. 